\title{
Variation in concentrations of major bioactive compounds in Prunella vulgaris L. related to plant parts and phenological stages
}

\author{
Yuhang Chen ${ }^{1,2}$, Zaibiao Zhu ${ }^{1}$, Qiaosheng Guo ${ }^{1,}{ }^{*}$, Lixia Zhang ${ }^{1}$ And Xiaoming Zhang ${ }^{1}$ \\ ${ }^{1}$ Institute of Chinese Medicinal Materials, Nanjing Agricultural University, Nanjing 210095, PR China \\ ${ }^{2}$ College of Pharmaceutical Sciences, Chengdu Medical College, Chengdu 610083, PR China.
}

\begin{abstract}
Prunella vulgaris L. (Labiatae) contains a variety of structurally diverse natural products, primarily rosmarinic acid (RA), ursolic acid (UA) and oleanolic acid (OA), which possess a wide array of biological properties. In the present study, P. vulgaris was harvested at three developmental stages (vegetative, full-flowering and mature-fruiting stages), dissected into stem and leaf tissues and assayed for chemical contents using high performance liquid chromatography. Significant changes in the concentrations of the major secondary metabolites (RA, UA and OA) were observed at the different development stages. The highest concentrations of RA, UA and OA were found at the full-flowering stage ( $15.83 \mathrm{mg} / \mathrm{g}$ dry weight (DW) RA, $1.77 \mathrm{mg} / \mathrm{g}$ DW UA and $0.65 \mathrm{mg} / \mathrm{g}$ DW OA). Among the different aerial parts of the plant, the concentrations of RA, UA and OA were higher in the leaves than in the stems at the different developmental stages. These results suggest that the full-flowering stage is characterized by the highest concentrations of bioactive compounds. Therefore, this stage may be the optimum point for harvesting P. vulgaris plants. In additional, the leaves of $P$. vulgaris demonstrated higher RA, UA and OA concentrations than the stems, suggesting higher utilization potential.
\end{abstract}

Key terms: Prunella vulgaris L.; ontogenetic and morphogenetic variation; rosmarinic acid; ursolic acid; oleanolic acid

\section{INTRODUCTION}

Prunella vulgaris L. (Labiatae), also known as the "self-heal", is a perennial herb widely distributed throughout eastern Asia and Europe (Flora of China, 1977). In China, P. vulgaris is primarily located in the southern provinces, particularly in the Anhui, Jiangsu, Henan and Zhejiang provinces (Chen et al., 2010). The dried spica of P. vulgaris, Prunellae Spica, is a standard medicinal material in the Chinese pharmacopoeia ("Pharmacopoeia of the People's Republic of China", 2010) and is occasionally used as an herbal medicine for alleviating sore throat, reducing fever and accelerating wound healing (Pinkas et al., 1994; Marková et al., 1997; Cheung and Zhang, 2008). Recent studies have demonstrated that methanol or water extracts of this herb exhibit many bioactive properties, including antihyperglycemic activity (Zheng et al., 2007), UV-A radiation photoprotection (Psotova et al., 2006), systemic anaphylaxis inhibition (Kim et al., 2007), immune modulation (Fang et al., 2005) and antioxidative, antiviral and antibacterial effects (Psotova et al., 2003). In addition to the pharmaceutical uses of $P$. vulgaris, the air-dried plants are used as an additive in some functional beverages, and the fresh leaves are also edible and often show up in vegetable recipes in southeast China (Chen et al., 2011; Chen et al., 2012).

P. vulgaris is rich in phenolic acids (Psotova et al., 2003). Rosmarinic acid (RA: Fig.1), the major phenolic component of $P$. vulgaris, which exhibits a wide spectrum of biological activities (Holzmannova, 1996), including lipoperoxidation suppression (Laranjinha et al., 1994), scavenging superoxide radicals (Osakabe et al., 2002) and antioxidant (Psotova et al., 2003) and anti-inflammatory (Osakabe et al., 2004) effects. The Chinese Pharmacopoeia 2010 considers RA to be the only criterion for the quality control of Prunellae Spica. In addition, triterpenes are the dominant compounds in P. vulgaris (Cheung and Zhang, 2008). Of the triterpenes, ursolic acid (UA: Fig.1) and oleanolic acid (OA: Fig.1) are most prevalent in P. vulgaris and exhibit many bioactivities, including hepatoprotection, anti-hyperglycemia and antifungal, antitumor and antiinflammatory effects (Liu, 1995). There is increasing evidence that UA is the main active substance in anti-diabetic medicines due to its ability to lower blood sugar, urine sugar, water intake and urine volume. In addition, OA has been reported to be the main compound that protects liver sickness (Liu et al., 2003).

Previous phytochemical studies on the bioactive components of $P$. vulgaris have reported the isolation of triterpenoids, phenolics, flavonoids, tannins, caffeic acids, the anionic polysaccharide prunelline and essential oils (Lamaison et al., 1991; Xu et al., 1999; Wang et al., 2000; Ryu et al., 2000; He et al., 2007; Zhang et al., 2011). Because secondary metabolites are particularly prone to qualitative and quantitative variations depending on factors such as genetic drift, physiological conditions, season and harvesting time, as well as analytical methods and sample preparation techniques, numerous investigations concerning the influence of the aforementioned factors have been conducted (Guo et al., 2010; Wu et al., 2010; Liao et al., 2010; Chen et al., 2011; Wang et al., 2011). The phenological stage of the plant is another source of variance that considerably influences its concentration of secondary metabolites (Liu et al., 2010). However, the knowledge of the potential contribution of the phenological stage is still lacking, and the few papers that have been published regarding this topic have focused on particular plant components and/or species (Wang et al., 1994; Luo et al., 2005; Jiang et al., 2009). 
We reasoned that the developmental stage of $P$. vulgaris at harvest might influence the concentration of secondary metabolites in the aerial parts of the plant and affect the quality of the harvested plant material. Therefore, the aim of the present study was to analyze the RA, OA and UA content of different aerial parts of $P$. vulgaris at various stages of development.

\section{METHODS}

\subsection{Plant material}

Seeds of P. vulgaris were collected from Queshan County, Henan Province, P. R. China. Twenty seeds of approximately the same size were sown in separate pots on October 7, 2008 and germinated in the greenhouse. One month later, the seedlings were transplanted to an experimental field located at a flat land site $\left(117^{\circ} 23^{\prime} \mathrm{E}, 31^{\circ} 24^{\prime} \mathrm{N}, 48.64\right.$ altitude) in Lujiang County, Anhui Province, P. R. China. The spacing was $30 \mathrm{~cm}$ between the rows and $25 \mathrm{~cm}$ between the plants within a row. The field was cultivated using conventional commercial methods from October 2008 to June 2009.

The plant material of $P$. vulgaris was collected from April to June 2009. The material represented 20 randomly gathered plants from three phenological stages: vegetative, full-flowering and mature-fruiting. Newly emerged shoots (5-6 months old) with leaves were harvested at the vegetative stage (April 10). At the full-flowering stage, only shoots with fully opened flowers were harvested (May 20). At the maturefruiting stage, only shoots that had red-brown spicas were harvested (June 15). The top of $2 / 3$ of the plant was harvested between 11:00 AM and 1:00 PM. After collection, 10 individuals were kept as whole plants. The rest of the plants were dissected into leaf and stem tissues, dried at room temperature (25 \pm $2^{\circ} \mathrm{C}$ ), ground and passed through a $0.3 \mathrm{~mm}$ sieve and assayed for RA, UA and OA content using HPLC.

\subsection{Chemicals and reagents}

HPLC-grade methanol was purchased from Fisher Scientific (Fisher Scientific Co., Fair Lawn, NJ, USA). Deionized water was purified using the Milli-Q system (Millipore, Bedford, MA, USA). Analytical-grade phosphoric acid and ethanol were purchased from Nanjing Liudu Fine Chemicals Co. Ltd. (Nanjing, China). Three authentic standards of RA, UA and OA were purchased from the National Institute for Control of Biological and Pharmaceutical Products (Beijing, China).

\subsection{Apparatus and analytical conditions}

HPLC was performed with a chromatographic pump (LC20AT), a manual sample injector, and a diode array detector (SPD-M20A, Shimadzu, Kyoto, Japan). The HPLC fingerprint was performed on a C18 column (Shimadzu, ODS-C18, 4.6 $\mathrm{mm} \times 250 \mathrm{~mm}, 5 \mu \mathrm{m})$ at $25^{\circ} \mathrm{C}$, with a sample injection volume of $10 \mu \mathrm{L}$. The data were collected with a model N2000 chromatography workstation (Zhejiang University, Hangzhou, China).

The chromatographic conditions used to detect the UA and OA components were as follows: the detection wavelength was $210 \mathrm{~nm}$ for the analysis; the flow rate of the mobile phase, consisting of methanol and $0.5 \%$ ammonium acetate (90:10, $\mathrm{v} / \mathrm{v}$ ), was $0.6 \mathrm{~mL} \cdot \mathrm{min}^{-1}$; and the column temperature was maintained at $25^{\circ} \mathrm{C}$. The chromatographic conditions for the RA component were as follows: the detection wavelength was $330 \mathrm{~nm}$; the flow rate of the mobile phase, consisting of methanol and $0.01 \%$ aqueous phosphoric acid (52:48,
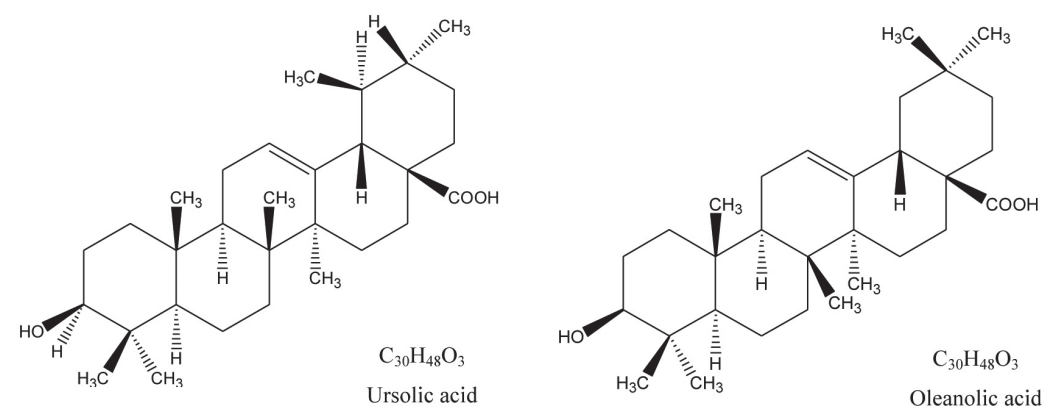<smiles>O=C(/C=C/c1ccc(O)c(O)c1)OC(Cc1ccc(O)c(O)c1)C(=O)O</smiles>

$\mathrm{C}_{18} \mathrm{H}_{16} \mathrm{O}_{8}$

Rosmarinic acid

Fig. 1. Chemical structure of ursolic acid (UA), oleanolic acid (OA) and rosmarinic acid (RA).

TABLE 1

Calibration curves of RA, UA and OA standard chemicals

\begin{tabular}{lccc}
\hline Standard chemicals & Equations & $R^{2}$ & Linear range \\
\hline Rosmarinic acid (RA) & $y=627449 x+261857$ & 0.9998 & $2.56-10.61$ \\
Ursolic acid (UA) & $y=60884 x-12642$ & 0.9996 & $1.40-5.60$ \\
Oleanolic acid (OA) & $y=56127 x-2087.4$ & 0.9995 & $1.15-4.60$ \\
\hline
\end{tabular}

$y$ : peak area; $x$ : concentration of chemicals $\left(\mu \mathrm{g} \cdot \mathrm{mL}^{-1}\right)$. 
$\mathrm{v} / \mathrm{v}$ ), was $1.0 \mathrm{~mL} \cdot \mathrm{min}^{-1}$; and the column temperature was maintained at $25^{\circ} \mathrm{C}$.

\subsection{Calibration curves of active constituents}

Stock solutions of RA, UA and OA were prepared in deionized water and diluted to six different concentrations using $75 \%$ methanol to construct the calibration plots. The linearity of each standard curve was confirmed by plotting the peak area (y) against the corresponding concentration $\left(x, \mu \mathrm{g} \cdot \mathrm{mL}^{-1}\right)$ of the analytes. The regression equations are listed in Table 1.

\subsection{Preparation of sample solutions}

The samples for HPLC were prepared using a modification of the methods of Fang et al. (2010). Powdered spica samples (0.10 g) were mixed with $20 \mathrm{~mL}$ of $75 \%$ methyl alcohol for $30 \mathrm{~min}$, extracted through a $30 \mathrm{~min}$ ultrasonic treatment at $20^{\circ} \mathrm{C}$ and centrifuged at $10,000 \mathrm{rpm}$ for $10 \mathrm{~min}$. The supernatant of the centrifugate was filtered through a $0.45 \mu \mathrm{m}$ organic membrane before it was injected into the HPLC system.

\subsection{Statistical analysis}

All the data were analyzed using SPSS 11.5 for Windows. The data were initially compared by an analysis of variance (ANOVA), and differences between means were detected using the Duncan test. $p$ values $\leq 0.05$ were considered significant.

\section{RESULTS AND DISCUSSION}

\subsection{Phenological changes in the RA, UA and OA concentrations of whole plants}

Phenological changes in the RA, UA and OA concentrations of whole plants were found to be significant $(p<0.05)$ in $P$. vulgaris. The concentrations of RA, UA and OA in samples of the whole plant increased during the course of ontogenesis. The highest level of those compounds was observed at the full-flowering stage $(15.83 \mathrm{mg} / \mathrm{g}$ DW RA, $1.77 \mathrm{mg} / \mathrm{g}$ DW UA and $0.65 \mathrm{mg} / \mathrm{g}$ DW OA). After the development of flowers, the concentrations of bioactive compounds decreased with the advancement of reproductive development (Table 2).

These results are in agreement with most of the previous work on the topic, which has reported that the full-flowering stage is characterized by the highest content of secondary metabolites. For example, Ayan et al. (2007) reported that the total phenol content reached its highest level at full-flowering in Hypericum pruinatum. Additionally, Verma and Kasera (2007) indicated that the peak concentration of phenols was observed at the flowering stage in Boerhavia diffusa. Similar results were also found by Sellami et al. (2009) in Origanum majorana, in which the highest levels of volatile terpenes occurred at the budding and full-flowering stages. These results could be explained by the low rate of biosynthesis of bioactive compounds during the vegetative stage, which may be due to the partial inactivation of enzymes necessary for the biosynthesis of certain compounds. Indeed, in previous studies conducted on members of the Lamiaceae family (primarily Herba rabdosia Serrae and Rabdosia rubescens), Chen et al. (2003) and Wu et al. (2004) reported that the UA and RA concentrations increased during plant development and reached their maximum levels during the flowering stage. Our findings in the present study confirmed this observation. The RA, UA and OA concentrations of whole plants increased during several ontogenetic development phases, and the highest level of those compounds was reached at the fullflowering stage in P. vulgaris.

The observed variations of phenolic acid and triterpene concentration during the growth of $P$. vulgaris affirmed the influence of phenological stages on the production and release of these metabolites. The peak amounts of the accumulation of RA, UA and OA observed during the full-flowering stage may be because, during this stage, the protection of the plant is achieved primarily by these phenolics and triterpenes. Indeed, it is well known that an important function of triterpenes and phenolic acids is their activity in plant defense mechanisms (Dixon and Paiva, 1995; Grassmann et al., 2002). However, the accumulation of triterpenes and phenolic acids during the full-flowering stage might also be related to ecological functions, such as the intensification of antifungal defenses and the attraction of pollinators (Langenheim, 1994). Regarding these variations in the accumulation of secondary metabolites in P. vulgaris, it is possible that the developmental stage of the plant affects the choice of the optimal harvesting time. For the maximization of RA, UA and OA concentrations, $P$. vulgaris plants should be harvested at the full-flowering stage.

\subsection{Phenological changes in the RA,UA and $O A$ concentrations of different aerial parts}

The differences in the RA, UA and OA concentrations of stem and leaf tissues during $P$. vulgaris development were also found to be significant $(p<0.05)$. In general, the highest levels of these compounds were achieved at the full-flowering stage in all the plant parts. The highest concentration of RA (Fig. 2C) was found at full-flowering stage, for example, but the

\section{TABLE 2}

RA, UA and OA concentrations in whole plants of $P$. vulgaris at different developmental stages (mg/g DW)

\begin{tabular}{lccc}
\hline Phenology & RA & UA & OA \\
\hline Vegetative & $7.82 \pm 0.06 \mathrm{c}$ & $0.98 \pm 0.12 \mathrm{c}$ & $0.21 \pm 0.01 \mathrm{c}$ \\
Full-flowering & $15.83 \pm 0.17 \mathrm{a}$ & $1.77 \pm 0.05 \mathrm{a}$ & $0.65 \pm 0.03 \mathrm{a}$ \\
Mature-fruiting & $10.91 \pm 0.11 \mathrm{~b}$ & $1.32 \pm 0.07 \mathrm{~b}$ & $0.39 \pm 0.08 \mathrm{~b}$ \\
\hline
\end{tabular}

Plant material, representing a total of 10 individuals, includes leaves and stems for the vegetative stage, reproductive parts, leaves and stems for the full-flowering stage and leaves, stems and red-brown spicas with seeds for the mature-fruiting stage. RA, rosmarinic acid; UA, ursolic acid; OA, oleanolic acid. Values followed by different small letters are significantly different $(p<0.05)$ according to the Duncan Multiple Range Test. 
concentration was higher in the leaves $(28.16 \mathrm{mg} / \mathrm{g}$ DW) than in the stems $(21.70 \mathrm{mg} / \mathrm{g}$ DW). Similar results were obtained for these plant organs during both the vegetative and maturefruiting stages. The RA content in the leaves of both the vegetative and mature-fruiting stages was found to be $38.79 \%$ and $83.92 \%$ higher than that found in the stems, respectively.

UA and OA (Fig. 2A-B) reached their highest concentrations during the full-flowering stage in leaves $(3.32$ and $1.90 \mathrm{mg} / \mathrm{g}$ DW, respectively). Specifically, the UA levels of the leaves were
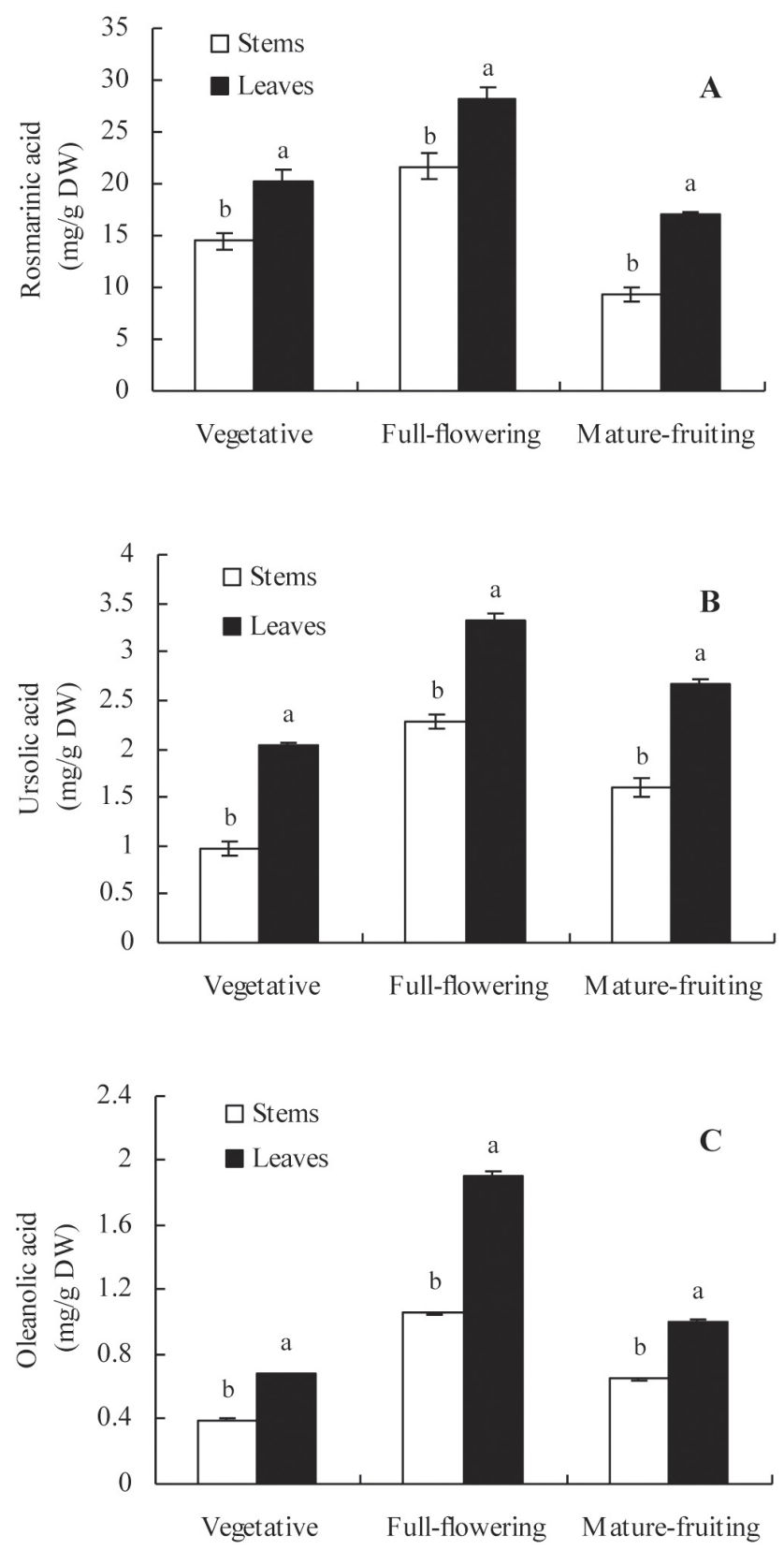

Fig.2. Phenologic changes of rosmarinic acid (A), ursolic acid (B) and oleanolic acid (C) concentrations in the stems and leaves of P. vulgaris. (Different letters above the columns indicate significant differences of compound concentration at different development stages at the level of $p<0.05$; bars are \pm s.e.).
$112.50 \%$ higher in the vegetative stage, $46.26 \%$ higher in the full-flowering stage, and $66.25 \%$ higher in the mature-fruiting stage, respectively, in comparison with the stem concentrations. Similarly, in comparison with the stem concentrations, the OA concentrations in the leaves were $70.63 \%$ higher in the vegetative stage, $80.05 \%$ higher in the full-flowering stage, and $54.89 \%$ higher in the mature-fruiting stage, respectively.

In the full-flowering stage, the proportions of RA, UA and $\mathrm{OA}$ in the stems and leaves of $P$. vulgaris were at their maximum measured levels, and the amounts of these bioactive components were significant higher in the leaves of the plant than in its stems. The aerial portions of $P$. vulgaris grew vigorously during this experiment. Large amounts of anabolites were produced, accumulated and transported to the reproductive parts of the plant, which also grew quickly. It was speculated that the RA, UA and OA in P. vulgaris were synthesized initially in the leaves and then transported to the inflorescences for storage via the phloem of the veins and the stem vascular bundles. Liu et al. (2010) reported that the highest UA and OA content in the stems and leaves of $P$. vulgaris plants occurred at the full-flowering and postflowering stages. Similarly, Zhang et al. (2007) demonstrated that the RA content of $P$. vulgaris leaves was higher than that of the stems at the flowering and mature-fruiting stages. Similar results were also found in other species of the Lamiaceae family, including in Rabdosia eriocalyx (Dunn) Hara (Gao and Yuan, 2009), Lavandula angustifolia Mill (Zou, 2010) and Mesona chinensis Benth (Leng, 2011).

In the mature-fruiting stage of $P$. vulgaris, the concentration of RA, UA and OA in the stems and leaves decreased dramatically. This phenomenon may be due to the rapid consumption of nutrients by the developing reproductive organs, which would cause a rapid decrease of these bioactive components in the stems and leaves. We determined that the RA, UA and OA levels in mature $P$. vulgaris spicas were $37.64,2.58$, and $0.78 \mathrm{mg} / \mathrm{g}$, respectively (Chen et al., 2012). These observations indicated that the decrease of RA, UA and OA content in the stems and leaves is closely related to the reproductive growth of $P$. vulgaris. These results are in agreement with the existing literature (Liu et al., 2010).

These results indicate high levels of variability, which are associated with the stage of plant development, in the content of the investigated bioactive compounds. According to Luckner (1980), as plant maturation progresses, there appears to be an ordered expression of the genome such that particular enzymes or group of enzymes are synthesized or activated at particular stages of plant development. According to our results, it appears that the aerial parts of $P$. vulgaris should be harvested during the full-flowering stage, during which they are the richest in RA, UA and OA.

\section{ACKNOWLEDGEMENTS}

This research was supported by the programs of National Nature Science Foundation of China (No. 30772730 and 81072986)

\section{REFERENCES}

AYAN AK, YANAR P, CIRAK C, BILGENER M (2007) Morphogenetic and diurnal variation of total phenols in some Hypericum species from Turkey during their phenological cycles. Bangladesh J Bot 36: 39-46. 
BOARD of PHARMACOPOEIA of P.R. CHINA (ed) (2010) Pharmacopoeia of the People's Republic of China. Chinese Edition 2010, Part I. China Medico-Pharmaceutical Science \& Technology Puhlishig House. Beijing, pp: 263.

CHEN SQ, DONG CM, ZHENG XK, DONG SL, WANG L, FENG WS (2003) The quantitative variety of rosmarinic acid in Rabdosia rubescens from different harvesting time. J Henan Univ Chin Med 18: 28-30.

CHEN YH, GUO QS, LIU L, LIAO L, ZHU ZB (2011) Influence of fertilization and drought stress on the growth and production of secondary metabolites in Prunella vulgaris L. J Med Plant Res 5: 1749-1755.

CHEN YH, GUO QS, ZHU ZB, ZHANG LX (2012) Changes in bioactive components related to the harvest time from the spicas of Prunella vulgaris. Pharm Biol, DOI: 10.3109/13880209.2012.658477.

CHEN YH, GUO QS, WANG CY (2010) Textual research on change of medicinal parts and herbal medicine of Prunella vulgaris. Chin J Chin Materia Med 35: 242-246.

CHEUNG HY, ZHANG QF (2008) Enhanced analysis of triterpenes, flavonoids and phenolic compounds in Prunella vulgaris L. by capillary zone electrophoresis with the addition of running buffer modifiers. J Chromatogr A 1213: 231-238.

DIXON RA, PAIVA NL (1995) Stress-induced phenylpropanoid metabolism. Plant Cell 7: 1085-1097.

EDITORIAL BOARD for FLORA of CHINA (1977) Flora of China. Science Press, Beijing, pp: 387.

FANG L, LIN NM, WU YJ (2010) Simultaneous determination of four active components in Spica Prunellae by HPLC. China J Chin Materia Med 35: 616-619.

FANG XY, YU MMS, YUEN WH, ZEE SY, CHANG RCC (2005) Immune modulatory effects of Prunella vulgaris L. Int J Mol Med 15: 1109-1116.

GAO WF, YUAN WJ (2009) HPLC determination of oleanolic acid and ursolic acid in different parts of Rabdosia eriocalyx (Dunn) Hara. Chin Pharm J Anal 29: 1947-1949.

GRASSMANN J, HIPPELI S, ELSTNER EF (2002) Plant's defence and its benefits for animals and medicine: role of phenolics and terpenoids in avoiding oxygen stress. Plant Physiol Biochem 40: 471-478.

GUO QS, ZHOU LJ, GONG WH, WU XS (2010) Effect of different water treatments on quality and yield of spadix in Prunlla vulgaris. China J Chin Materia Med 35: 1795-1798.

HE LJ, LIANG YZ, ZHAO CX (2007) GC/MS study on chemical constituents of essential oil of Lemiaceae plants. Acta Chim Sinica 65: 223-232.

HOLZMANNOVA V (1996) Rosmarinic acid and its biological activity. Chem Listy 90: 486-496.

JIANG XZ, WU YZ, ZHANG DR, LIU W (2009) Cultivated techniques of Prunella vulgaris under good agriculture practice. J Jiangxi Univ Tradit Chin Med 21: 79-82.

KIM SY, SHIN HY, LIM JP, CHAE BS, PARK JS, HONG SG, KIM MS, JO DG, PARK WH, SHIN TY (2007) Effects of Prunella vulgaris on mast cellmediated allergic reaction and inflammatory cytokine production. Exp Biol Med 232: 921-926.

LAMAISON JL, PETITJEAN-FREYTET C, CARNAT A (1991) Medicinal Laminaceae with antioxidant properties, a potential source of rosmarinic acid. Pharm Acta Helv 66: 185-188.

LANGENHEIM JH (1994) Higher plant terpenoids: a phytocentric overview of their ecological roles. J Chem Ecol 20: 1223-1280.

LARANJINHA JAN, ALMEIDA LM, MADEIRA VMC (1994) Reactivity of dietary phenolic acids with peroxyl radicals: antioxidant activity upon low density lipoprotein peroxidation. Biochem Pharmacol 48: 487-494.

LENG GH (2011) Determination of oleanolic acid and ursolic acid in different parts of Mesona Chinensis Benth by RP-HPLC. Chin J Spectrosc Lab 28: 2111-2114.

LIAO L, LIU L, GUO QS, WANG ZY, CHEN YH (2010) Morphological and chemical variation of Prunella vulgaris populations from different locations in China. Chin Herb Med 2: 305-311.

LIU HX, SHI YH, WANG DX, YANG GL, YU AM, ZHANG HQ (2003) MECC determination of oleanolic acid and ursolic acid isomers in Ligustrum lucidum Ait. J Pharm Biomed Anal 32: 479-485.

LIU J (1995) Pharmacology of oleanolic acid and ursolic acid. J Ethnopharmacol 49: 57-68.
LIU P, YUAN BG, YIN DD, MIAN F (2010) Accumulation Laws of main medicinal ingredients in different part of Prunella vulgaris L. Acta Agri Boreali-Occidentalis Sin 19: 137-140.

LUCKNER M (1980) Expression and control of secondary metabolism. In: BELL EA, CHARLWOOD BV (eds) Secondary Plant Products. Heidelberg: Springer-Verlag. pp: 23-63.

LUO MH, ZHOU RB, TONG QZ, QU WH (2005) A Study on the optimum picking period for Prunella vugaris L. cultivated in a standardized way. J Hunan Univ Tradit Chin Med 25: 12-14.

MARKOVA H, SOUSEK J, ULRICHOVA J (1997) Prunella vulgaris L.-a rediscovered medical plant, Ceska Slov Farm 46: 58-63.

OSAKABE N, TAKANO $\mathrm{H}$, SANBONGI C, YASUDA A, YANAGISAWA R, INOUE K, YOSHIKAWA T (2004) Anti-inflammatory and antiallergic effect of rosmarinic acid (RA); inhibition of seasonal allergic rhinoconjunctivitis (SAR) and its mechanism. BioFactors 21: 127-131.

OSAKABE N, YASUDA A, NATSUME M, SANBONGI C, KATO Y, OSAWA T, YOSHIKAWA T (2002) Rosmarinic acid a major polyphenolic component of Perilla frutescens, reduces lipopolysaccharide (LPS)induced liver injury in D-galactosamine-sensitizied mice. Free Radic Biol Med 33: 798-806.

PINKAS M, TROTIN F, PENG M, TROCK M (1994) Use chemistry and pharmacology of the Chinese medicinal plants. Fitoterapia 55: 343-353.

PSOTOVA J, KOLAR M, SOUSEK J, ŠVAGERA Z, VICAR J, ULRICHOVA J (2003) Biological activities of Prunella vulgaris extract. Phytother Res 17: 1082-1087.

PSOTOVA J, SVOBODOVA A, KOLAROVA H, WALTEROVA D (2006) Photoprotective properties of Prunella vulgaris and rosmarinic acid on human keratinocytes. J Photochem Photobiol B: Biol 84: 167-174.

RYU SY, OAK MH, YOON SK, CHO DI, YOO GS, KIM TS, KIM KM (2000) Anti-allergic and anti-inflammatory triterpenes from the herb of Prunella vulgaris. Planta Med 66: 358-360.

SELLAMI IH, MAAMOURI E, CHAHED T, WANNES WA, KCHOUK ME, MARZOUK B (2009) Effect of growth stage on the content and composition of the essential oil and phenolic fraction of sweet marjoram (Origanum majorana L.). Ind Crops Prod 30: 395-402.

VERMA V, KASERA PK (2007) Variations in secondary metabolites in some arid zone medicinal plants in relation to season and plant growth. Indian J Plant Physiol 12: 203-206.

WANG HB, ZHANG ZY, SU ZW, LI CH (1994) Herbalogical Study on Common Selfheal (Prunella vulgaris). Chin Tradit Herbal Drugs 25: 213214.

WANG YX, YIN JB, GUO QS, XIAO YH (2011) Dynamic change of active component content in different parts of Prunella vulgaris. China J Chin Materia Med 36: 741-745.

WANG ZJ, ZHAO YY, WANG B, AI TM, CHEN YY (2000) Depsides from Prunella vulgaris. Chin Chem Letters 11: 997-1000.

WU JF, LIU B, ZHU CC, LAI XP (2004) Determination of $2 \alpha$-hydroxy-ursolic acid from Herba rabdosiae Serrae in various collecting periods. Chin Tradit Herbal Drugs 35: 81-83.

WU Z, GUO QS, WANG QY, ZHOU LJ, ZHANG ZY, ZHANG LX, HUANG $\mathrm{T}$ (2010) Effects of lead, copper and cadmium stresses on growth and inherent quality of Prunalla vulgaris. China J Chin Materia Med 35: 263267.

XU HX, LEE SHS, LEE SF, WHITE RL, BLAY J (1999) Isolation and characterization of an anti-HSV polysaccharide from Prunella vulgaris. Antiviral Res 44: 43-54.

ZHANG GW, HE L, HU MM (2011) Optimized ultrasonic-assisted extraction of flavonoids from Prunella vulgaris L. and evaluation of antioxidant activities in vitro. Innov Food Sci Emerg 2: 18-25.

ZHANG LZ, QIN W, ZHANG XH (2007) Assay method for contents of caffeic acid and rosmarinic acid in the different parts of Prunella vulgaris L. Beijing Univ Trad Chin Med 30: 343-345.

ZHENG J, HE JG, JI BP, LI Y, ZHANG XF (2007) Antihyperglycemic activity of Prunella vulgaris L. in streptozotocin-induced diabetic mice. Asia Pac J Clin Nutr 16: 427-431.

ZOU SQ (2010) Determination of oleanolic acid and ursolic acid in the different parts of Lavandula angustifolia Mill.by HPLC-PAD. Chin Pharm J 45: 949-951. 
